\title{
FROM PARTNERS TO PLAYERS: EXTENDING THE HR PLAYING FIELD
}

\author{
Dave Ulrich and Dick Beatty
}

HR professionals must always be "becoming" or constantly changing and adapting. For the last decade, many have argued the business partner role as a complement to traditional HR administrative work. We argue in this paper that HR professionals should move beyond partners to become players. HR professionals as players are "in the game, on the field, making a difference" through their HR work. In this article, we suggest that to become players, HR professionals must learn to coach, architect, build, facilitate, lead, and provide a conscience to business leaders. Specific knowledge and tools for each of these roles are described. (C) 2001 John Wiley \& Sons, Inc.

\section{Introduction}

The HR partner concept has been popular for over a decade and is described in several works, most notably in Ulrich and Lake's Organizational Capability (1990). This concept recognizes that for the HR field to move beyond its polite (people focused) and police (regulation focused) roles and add value to executing a firm's strategy, it needs to:

1. Know the business.

2. Become an expert in HR basics (the function's "tool kit").

3. Learn how to use these tools to change the organization's culture and strategic capabilities through effective and efficient development of its workforce.

More recently, Beatty and Schneier (1996) began to describe a shift in the role of the HR professional as moving from HR partners to players as required for HR to meet a firm's strategic challenges.

The shifting role of HR comes from changing business demands. Organizations must establish new covenants with customers (Heskett \& Schlesinger, 1994), manage disruptive technologies (Christensen \& Overdorf, 2000), create new forms of engagements with employees, and face scrutiny of investors who determine a firm's market value by assessing its intangibles, not just its present or past earnings. The sum of these changes requires evolution in the HR role. HR professionals will have to continue to deal with concepts relating to talent and intellectual capital. They will have to ensure both competent and committed employees for the future not the past. In addition, however, HR professionals will need to help organizations change and change quickly, innovate, develop
HR professionals will have to continue to deal with concepts relating to talent and intellectual capital. 
leadership depth, ensure accountability, learn and un-learn, leverage global knowledge, create strategic clarity, establish customer intimacy, etc. These new deliverables of HR become capabilities of the firm of the future and intangibles which instill investor confidence.

To meet these increased expectations, HR professionals must be more than partners; they must be players. Players contribute. They are engaged. They add value. They are in the game, not at the game. They deliver results. They do things that make a difference.

We propose six ways in which HR players contribute to the organization: coach, architect, builder, facilitator, leader, and conscience. HR players who master these roles add value and contribute to an organization's ability to compete in a significantly expanded playing field. To win on this extended playing field will significantly test traditional HR professionals. We want to suggest specific concepts and actions for each of these six roles so that future HR professionals can meet the increasing demands placed on them (see Figure 1).

\section{The HR Coach: Coaching to Win}

\section{Why Coaches Matter}

Coaches exist in all walks of life. Coaches like John Wooden are masters at observing behavior, describing behavior, providing feedback, and rewarding behavioral change. HR coaches have this opportunity both within their own function and more importantly they can coach executives in changing their behavior. Coaches help people improve, see what works and what doesn't, and offer special counsel and advice to enable executives to develop themselves and improve organizational performance.

Coaching also focuses on attitudes, as well as behaviors. Coaches serve as teachers, and the best coaches help their pupils to become teachers of what is necessary for the organization to succeed. They know when to be critical and when to be positive, and when to be supportive and nurturing. Most important, they know both how to stimulate the appropriate individual behavior and to encourage team play; ultimately they know how to enable the team to win. They may not always be popular, but the best coaches deliver results and are held accountable for these results. Thus one major role of the HR player as coach is to enable professional growth and to help executives achieve their full potential in guiding the firms' business success on the various performance scorecards.

Coaches know the game, and they know how to win. They understand not only how the score is kept but also the capabilities, both team and individual, needed to score. Fully grasping and understanding the organization's stakeholder scorecard is critical. It includes familiarization not only with the components, but with the details - the activities to energize and strategic capabilities to build-within, the business scorecard (Figure 2). These components and details can also help to identify present and future sources of concern and thus help prioritize executive actions.

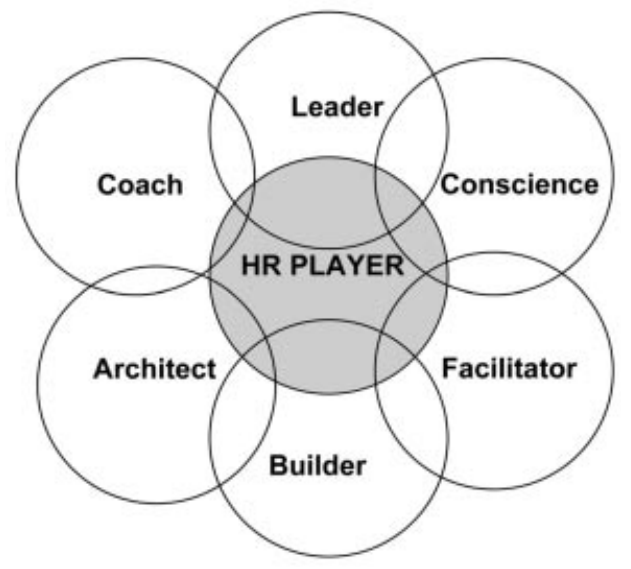

Figure 1. The interdependent role of the HR player. 
Figure 2. A winning business model.

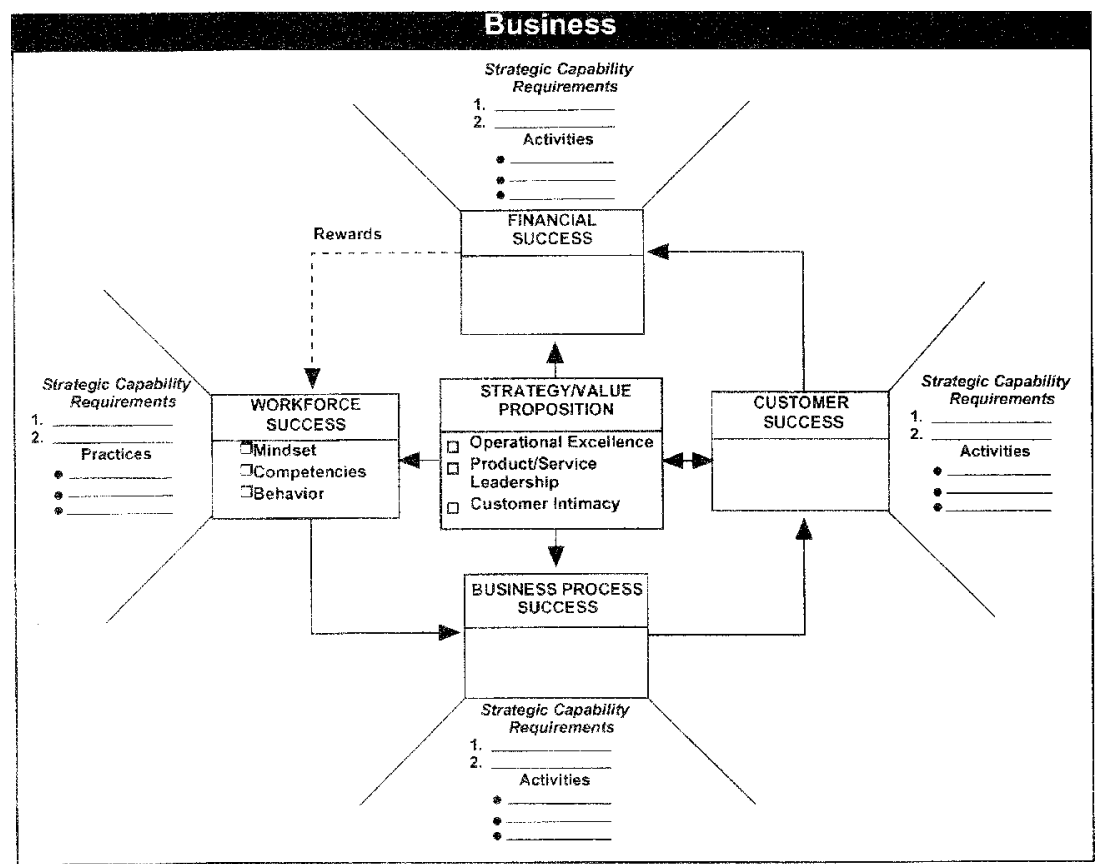

In coaching executives, one can begin with an examination of the stakeholder relationships to understand the executives' goals with each stakeholder, how these relate to each other in the firm's business model, and how to measure attainment of the goals (Figure 2). In coaching, HR players might ask an executive:

What are your goals with this stakeholder?

What is your current relationship with this stakeholder?

What is the relationship between this stakeholder and another stakeholder (e.g., customers and consumers)?

What needs to be adapted to reach your goals?

What actions can you take that will ensure that the goals are met?

What are the metrics for the success with each stakeholder?

These questions, as a part of the coaching conversation, may help the business leader focus attention and energy, prioritize actions, and, most importantly, confirm or craft a strategy.

In one firm, the senior business leader has been coached once every six months for two years. Each visit begins with the stakeholder map. He is asked how he has done recently with the stakeholders he was most concerned about in the last visit (e.g., customers, investors, etc.). He then creates plans to engage key stakeholders in the future. The stakeholder map has helped the business leader realize that he cannot be all things to all stakeholders all the time, but must consider priorities in the context of the relationship between stakeholders. It has also helped with the realization that attention to stakeholders evolves over time (e.g., as union relations were approaching contract time, more attention had to be allocated to this stakeholder and pulled back from others). As he matched stakeholder goals with his calendar and time, he was able to help him keep focused on the things that mattered most to him.

Coaching often requires courage and contracting. Many business leaders have not had personal coaches who offer them candid observations and as a result may be put off at first by intense coaching. When done well, however, coaching becomes an invaluable source of insight. In one large firm struggling with all the demands of becoming disintermediated through "new economy" e- 
HR players as coaches must also learn to give clear, direct, candid, and useful feedback to both the business leader and the team. business initiatives, the two business leaders were often in conflict about the direction to take the firm. The new head of HR asked for a meeting with them. He related that, in his brief time with the firm, a number of embedded problems stemmed from the conflict and difference of opinion between the two of them. These problems were not allowing the creation of a consistent set of business ideas as to how the firm would win in its future marketplace, which needed to be communicated to the employees and customers. At first, they disagreed, but as he shared specific cases, they came to realize that their inability to create a shared point of view about how to position the firm in the new economy was causing chaos within the firm. He then proceeded to help them through difficult, but candid conversations about their unique management styles, aspirations for the firm, and personal ambitions. He kept in front of them the importance of their converging around a common set of business ideas so that others in the firm could then align their behaviors. His bi-weekly meetings became a forum for honest discussion that the two senior leaders had not experienced. These conversations not only increased the HR executive's personal credibility, they enabled both executives to focus and respect each other's strengths and face and overcome weaknesses.

In a consumer goods firm a new CEO had emerged through the marketing side of the business and obtained the CEO position because he was excellent at "doing"-the execution of strategy. More frantic doing at a time when many of the firm's products were becoming commoditized, while helpful in some ways, did not enable the organization to build the strategic capabilities to win the firm's future. It required several coaching sessions to help the new CEO understand his new role not only as a marketer of present success but also as a builder of future success. Once understood, he engaged in an entirely new set of decisions, using a very different decision-making style.

\section{How to Coach}

For HR professionals to coach, they must build a relationship of trust with the business leader. This relationship emerges as the HR profes- sional expresses personal concern for the leader, empathizes with the leader's challenges, offers specific suggestions for the leader's actions, spends time with the leader both observing and sharing observations, and is willing to offer the leader feedback s/he may not receive elsewhere. In political organizations, few tell the leader what $\mathrm{s} /$ he does not want to hear. Coaches must find ways to share good news and bad with the trust that both messages are intended to help both the leader and company improve. Most of the leaders we coach find a coaching session (one hour a month or quarter) cathartic. They are able to have someone in their office who does not have an agenda, a request, or a self-enhancing point of view to pitch. They have someone in front of them who listens and wants only to help the executive think through options and improve the CEO's and the firm's performance.

HR players as coaches must also learn to give clear, direct, candid, and useful feedback to both the business leader and the team. Giving feedback requires knowing how the person will respond. One leader with whom we worked became defensive with feedback, so the comments needed to be couched in terms of future suggestions, not negative criticism. Another valued the direct and blunt feedback but then could not process it and turn it into behavioral change. We have learned that feedback works better if:

1. It is behavior based (e.g., examine what you did in this specific instance, which may also require firsthand observation).

2. Not generic ("You tend to not listen to employees").

3. It offers suggestions for improvement more than criticism ("In the future, you might try having more input on a decision before you make it").

4. Focuses on the future more than the past ("Why not try to begin the meeting with a question next time...").

5. Encourages reflection more than acceptance ("Here is what I perceive, how close is it to what you perceive?")

Trust also comes when the coach is able to express personal concern. In our coaching 
one of the important stakeholders is self. We often ask the question, "How are you taking care of yourself?" We have found executives who are so engaged in the business that personal relationships that matter are being avoided or discounted, and personal hobbies which give balance and fullness to life are being put on hold. We often legitimate taking time for self, which might mean taking a weekend retreat with a significant other, installing a telephone line no one else knows but family members who can call anytime, or legitimating personal renewal time. One executive confided to us that the pressure of the job was causing some insomnia, and it was worrying him. He could not share this with others on his management team, but we talked about it and encouraged him to spend time in off-work activities that lead to renewal. Taking care of self becomes an integral part of the coaching relationship.

\section{The HR Architect: Designing to Win}

\section{Why Architects Matter}

Both authors have built homes using an architect. We learned early and quickly the importance and role of architect in understanding our functional requirements. The architect sought to understand the outcomes we sought and to meet our requirements, such as positioning the house on the lot so that we had maximum privacy from neighbors, putting more square footage into rooms we were more likely to use (e.g., kitchen, family room, and offices) than not use (e.g., formal living room), having an easy traffic flow, strategically placing bedrooms for children and offices for adults, and building rooms according to our specifications. The architect continually pointed out choices that ensured that the house met our needs.

Architects provide the high-level blueprint. They help the organization identify ideas about how firms will win in chosen marketplaces and thus how to design significant next steps in competitiveness. This help includes identifying what are the cultures and capabilities (as with our own homes) required to enable the firm's ideas to create competitive success. There are two components to this. One may be a derivative of coaching whereby in working with the chief executive, unattached, uncoordinated, and uncommunicated ideas about what it will truly take to create a competitive advantage can be moved from merely loose concepts to a tightened strategy and a tight message for the organization. Clearly, the examples of General Electric from when Jack Welch inherited GE in the 1980s (e.g., centralized authority and power; stable, predictable growth, etc.) and where it is today in terms of business ideas about how they would win in the marketplace (to be No. 1 or No. 2 in their markets, empowered business units, etc.) have changed substantially. They have changed not only in the first ten years of his tenure, but the last ten years as well (e.g., ebusiness, organizational vitality, etc.). What is important to recognize is that these ideas have to be transferred into a general architecture within the workforce, both in terms of the culture and the strategic capabilities required to deliver those business ideas. These are difficult issues and ones for which a blueprint that is understandable and easily communicated to the workforce is critical because it addresses the basic issues found in any blueprint: Who are we and where are we going? Specifically, questions that have to be asked are, what is our strategy (and do we have one) and how we can communicate that to our workforce. Do we have the right organization in terms of culture and capabilities? Perhaps the next step, beginning to think about what roles must be played by management in an attempt to assure that the strategy, culture, and capabilities are aligned or manifested as intended.

Architects help turn general and generic ideas into blueprints for organizational action. They shape the way work flows consistent with the ideas and ideals of the business leader. They help identify choices not evident to the business leader about how organizations might be better governed. They help executive meetings better understand business realities and ensure that dialogue focuses on the right issues. With resources accessed through alliances more than ownership, they assure that organization capabilities cross boundaries. With employees behaving as volunteers, they
Architects help turn general and generic ideas into blueprints for organizational action. 
Organization architects know when and how to give choices and when and how to ensure compliance with regulation. help adopt new workforce policies to attract and retain such employees.

Organization architects possess multiple skills. They attend management meetings with an eye on the ways in which the organization should be aligned with strategy. They continually look for the strategic agenda of the firm and try to envision how it turns into an organizational agenda. In their management meetings, they offer ideas and alternatives about how to weld organization capabilities across alliances to deliver value to customers and employees. They perform organizational diagnoses by asking questions such as:

- Given our strategy, do we have the right organization?

- Given our strategy, what are the capabilities we must have to deliver the strategy in an effective and efficient way?

- Given our strategy, what roles must be played by management team members to ensure implementation?

These types of questions allow for organizational diagnosis to occur and focus attention on crafting improved organizations.

\section{What Architects Do}

In order for HR professionals to be organization architects, they must have a concept of organization and be able to apply that concept to the firm. A concept of organization means that they have a model of what constitutes an effective organization. An abundance of these models exists. McKinsey used the $7 \mathrm{~s}$ framework for organizational diagnosis for years. Jay Galbraith construed organizations into five dimensions or a "star"model: strategy, structure, rewards, processes, and skills.

For example, Pitney Bowes is shifting its strategy consistent with the b-economy. The firm has traditionally relied on product innovation as its key strategy agenda. It would embed products in messaging solutions or mail room services, and then upgrade those products as required by technology to ensure growth. In recent years, the CEO has refocused the firm on a strategy of customer intimacy. This strategy has focused on total messaging solutions for targeted firms, seeking to have a share of messaging revenue from targeted firms through intense service. The executive leadership team at Pitney Bowes worked to define the organizational identity and capabilities required to deliver this new strategy. After debate and dialogue, the leadership team concluded that the capabilities required were responsiveness, innovation, and total solutions. The team members wanted to create an identity among their targeted customers as the most responsive and innovative solution provider in the industry. They felt that if these capabilities desired by customers were embedded inside the firm, their strategy would happen. The architect of this work was the senior HR leader who helped the CEO turn a new reality strategy into a set of capabilities.

Architects are not owners, however. When we built a house with an oblong office, the architect pointed out liabilities of our anticipated choices, but we as owners maintained final choice. At other times, the architect would ensure that our desires were possible within code (e.g., electrical outlets, pitch of the staircase, heating and cooling systems, etc.). Likewise, HR professionals as organization architects may not own the organization, but they offer informed choice. For example, in Pitney Bowes transition to a customer centric strategy, the HR leaders laid out three alternative scenarios that the current CEO may follow. They pointed out pros and cons of each and helped the CEO and his team make the best choice for them. They own the choice. At other times, organization architects must ensure that action is congruent with current code or regulation. Hiring or paying someone must fit legal and ethical requirements. Organization architects know when and how to give choices and when and how to ensure compliance with regulation.

Often consultants serve as organization architects. We would argue that consultants may partner with input and advice, but internal HR players need to be primary architects for the organization to be successful. Internal architects are more sensitive to the needs of the firm; they are more likely to understand the subtleties required for a successful organization; and they are more attuned to the political realities of creating the right organization. 


\section{HR Builder: Constructing a Winner}

Why Builders Matter

HR players are also builders. Architects create blueprints, but those blueprints must be implemented to have impact. HR professionals contribute to the construction of a winning organization by understanding the work required to build competitive organizations. Clearly, once the strategies have been articulated and the capabilities delineated, the right work and the right work processes must be identified. HR builders must figure out how to work to deliver the value proposition to the firm's targeted customer constituency.

Building to win makes a great deal of difference, as can be seen in the chart from Beatty and Schneier (1996) that demonstrates that different value propositions require different work structures (Table I). Clearly, if the intent is to win through cost and price, a very tight structure and much more bureaucratic organization would be required. However, if the intent is to win through innovation, then a much looser structure may be required, especially in the components that design the innovative offerings to take to the marketplace. At the same time, not only must sufficient latitude be offered to functions such as $\mathrm{R} \& \mathrm{D}$, which create new product and service offerings, but the latitude to re-examine processes and think "outside the box" with respect to processes, as well. Finally, if organizations are pursuing strategies that are targeted towards "markets of one" (i.e., customized strategies), loose structures are often necessary, especially at the point of customer interface, to meet the needs of the customer in providing unique solutions.

Architects create blueprints, but without implementation, they become ideals without impact. Turning ideas into action matters because unless creative ideas are implemented, they add no value. Acting on ideas comes when employees who come to work behave in ways consistent with strategy and capability. To shape and encourage employee behavior, HR professionals design and deliver HR practices that both drive and reinforce behavior.

Psychologists have found that people behave differently due to information, behavior, and reinforcement. HR practices drive each of these three levers to shape how em-

\section{TABLE I}

\begin{tabular}{|c|c|c|}
\hline \multicolumn{3}{|c|}{ Strategic Choice and People "Fit" } \\
\hline $\begin{array}{l}\text { Operational Excellence } \\
\qquad- \text { Cost - }\end{array}$ & $\begin{array}{l}\text { Product Leadership } \\
\text { - Innovation- }\end{array}$ & $\begin{array}{c}\text { Customer Intimacy } \\
\text {-Solutions - }\end{array}$ \\
\hline \multicolumn{3}{|c|}{ Core Workforce Mindset } \\
\hline $\begin{array}{l}\text { - Identifies with process } \\
\text { - Trainable/can learn } \\
\text { - Follow the Battle Plan } \\
\text { - Dedicated to organization } \\
\text { - Shorter-term focus } \\
\text { - Avoid waste and cost } \\
\text { - Driven by incremental improvement } \\
\text { - High concern for output quantity } \\
\text { - High concern for process } \\
\text { - High comfort with stability } \\
\text { - Lower level of risk-taking }\end{array}$ & $\begin{array}{l}\text { - Identifies with, values and is humbled by } \\
\text { the discovery process } \\
\text { - Challenges the possible/the status quo } \\
\text { - Anti-bureaucratic } \\
\text { - Longer-term focus } \\
\text { - Versatile } \\
\text { - Driven by learning } \\
\text { - Higher concern for outcomes } \\
\text { - High tolerance for ambiguity } \\
\text { - Greater degree of risk-taking }\end{array}$ & $\begin{array}{l}\text { - Identifies with customers } \\
\text { - Shares "secrets" readily, easily } \\
\text { - Seeks customer intelligence } \\
\text { - Adaptable/flexible } \\
\text { - Makes customer results happen } \\
\text { - Quick study } \\
\text { - Driven by customer success } \\
\text { - Anticipates customer needs }\end{array}$ \\
\hline - NOT: Free spirits/ostentatious & - NOT: Structured/streamlined & - NOT: Clones \\
\hline \multicolumn{3}{|c|}{ Typical Behaviors } \\
\hline $\begin{array}{l}\text { - Teamwork } \\
\text { - Working to fit in/find a role } \\
\text { - Relatively repetitive and predictable } \\
\text { behaviors } \\
\text { - Primarily individual activity as part of } \\
\text { process }\end{array}$ & $\begin{array}{l}\text { - Problem solving } \\
\text { - Challenging one another } \\
\text { - Cross-functional collaboration } \\
\text { - High degree of creative behavior }\end{array}$ & $\begin{array}{l}\text { - Share ideas and solutions } \\
\text { - Thinks/works across boundaries } \\
\text { - Develops broad-based skills } \\
\text { - Networks effectively } \\
\text { - Customer management }\end{array}$ \\
\hline \multicolumn{3}{|c|}{ Examples } \\
\hline $\begin{array}{l}\text { Federal Express, Dell, Nucor, } \\
\text { Wal-Mart, UPS, Home Depot }\end{array}$ & $\begin{array}{l}\text { Glaxo, Merck, } 3 M \text {, Intel, Nike, Microsoft, } \\
\text { AstraZeneca, Novartis, Ralph Lauren, } \\
\text { Donna Karan }\end{array}$ & $\begin{array}{l}\text { Four Seasons, Airborne, Roadway, Cott, } \\
\text { Cable \& Wireless, Price-Waterhouse- } \\
\text { Coopers, McKinsey \& Co. }\end{array}$ \\
\hline
\end{tabular}


HR professionals as organization builders align, integrate, and innovate HR practices. ployee act. Information signals to employees those things that matter most. When new leaders are promoted, when some employees are paid more than others, and when leaders consistently share messages in their communications, signals are sent to employees throughout a firm about what matters most. HR professionals also build HR practices to send information cues to the workforce about what matters most. HR practices are a primary source of information signals to employees.

HR professionals as builders/designers know what employee actions are expected in the new organization, and they craft HR practices to ensure that these behaviors occur over time. HR practices become an infrastructure that shapes employee action through information, behavior, and reinforcement. At times this shaping is explicit (e.g., a communication message that encourages risk taking); other times the shaping is more embedded in the HR systems (e.g., promoting risk takers to senior jobs and paying risk takers more).

\section{What HR Builders Do}

HR professionals as organization builders align, integrate, and innovate HR practices. To do so requires that HR professionals identify domains of HR choices. Many typologies exist of categories or domains of HR practices. We have clustered HR choices into the following domains:

- Competence: choices related to hiring, promotion, career development, training, job assignments, job rotation

- Rewards and performance management: choices related to performance appraisal and standards measured and set, financial and nonfinancial rewards

- Communication: choices related to gathering and sharing information with both employees inside and stakeholders outside the firm

- Governance: choices in organization design and structure, use of high performing teams, and policies

- Change processes: choices in learning, making change happen, sharing ideas across boundaries, and institutionalizing change

HR professionals need to know, based on current theory and research, the choices in each of these categories. For example, they should know what the theory and research on competency models suggests for hiring, training, and paying leaders of virtual organizations.

In identifying choices in each of the domains, HR professionals create menus of choices that may be made to compete. Menus are often generated by those working in the centers of expertise. These menus offer a set of HR practices that can be used to align, integrate, and innovate HR. Each HR practice on the menu must be certified as innovative which means it must be based on latest theory, technology, and practice.

With menus in mind, alignment occurs as HR practices are matched to the strategy and capability of a business operation. At Pitney Bowes, their office product division that makes copiers and fax machines has a strategy of operational excellence in a price-sensitive market. The menu of HR practices allows this capability to be implemented through financial incentives tied to cost reduction. Another division striving to innovate in messaging solutions chooses financial incentives that encourage creativity and innovation.

With menus in mind, integration may also occur. Integration means that the HR practices share a common focus. Staffing, training, compensation, governance, and communication choices must be integrated and focused on common goals. In some companies, employees are hired with skills A, B, and $\mathrm{C}$; then they are trained to do D, E, and $F$; then paid for $\mathrm{G}, \mathrm{H}$, and I. No wonder employees are confused about their focus. With integration around key capabilities, staffing, training, compensation, and other HR practices all may be integrated around A, B, and C. This was the logic used by Ralph Christensen at Hallmark. Given the firm's strategy and capabilities, his HR team identified a core set of competencies required to ensure success. All HR practices then both aligned and integrated with these competencies. A similar message was sent to all employees as to what was expected of them. This 
message was reinforced through the HR practices and through the employee behaviors congruent with the HR practices.

HR builders of organizations implement HR practices with impact. By so doing, the blueprint they create as architects shapes employee action through information, behavior, and reinforcement. When this occurs, the desired organization is embedded in HR practices.

In order to design and deliver HR practices, HR players must be current in theory and practice of HR. They must know innovative HR practices deployed by other firms and be able to adapt those ideas to their firms. They need to stay current through active participation in professional associations where ideas are generated and shared. They need to follow the literature and keep abreast of theory and practice. We are continually appalled by the lack of HR knowledge of HR in their supposed areas of expertise that professionals demonstrate. For example, at a recent conference for Chief Learning Officers-those charged with developing learning agendas for their firms - we were asked how to spell Chris Argyris and to recommend his readings. We would not expect HR generalists to be cognizant of work by Argyris (and other learning theorists), but we would expect Learning Officers to be conversant with his ideas.

Often HR professionals are not active learners but followers of what others have done. We have advocated that HR professionals become "data miners", constantly screening existing literature and doing research within their own firms. With good research, HR professionals may prioritize HR practices that have the greatest impact. They know where to invest limited resources. They know how to measure impact of the HR investments they make. They become implementers of ideas they architect. They become not only experts at seeing what needs to be done but at making it happen.

\section{HR Facilitator: Changing the Organization to Win}

\section{Why Facilitators Matter}

Often HR players are not given a clean sheet upon which to build an organization, and the coaching and architecting involve remodeling. This is the role of the HR player as facilitator. Even with good intent, most change efforts fall short. Personal programs for weight loss, smoking cessation, or exercise are often like New Year's resolutions that begin with enthusiasm and end with quiet fizzles. Likewise, organization programs that begin with great fanfare become fads that lack sustainability. In the new business reality it would be easy to fall prey to chasing the latest fads, never to catch up.

The facilitator role clearly encompasses strategic change leadership. In many respects, we expect that the HR function will identify "strategic change leadership" of the firm's executives as a strategic capability. That is, all organizations can and must change. The issue is how, and the question is the role that the HR will play in change.

HR professionals as facilitators understand the importance of getting things done, making change happen, and sustaining that change at three levels. First, they help teams operate effectively and efficiently. Teams and teamwork are cornerstones of organizations both within the boundaries of the firm and across alliances. HR players as facilitators ensure that all types of teams have the capacity to focus, accomplish, and function effectively. Facilitators build, coach, and sustain teams. Teams that work well have the capacity to leverage individual excellence and to ensure collective performance. In the new business reality, teams are inevitable because no one person has access to all knowledge and information. If managed well, teams outperform individuals, and HR facilitators ensure team performance.

Second, facilitators ensure that organization change happens. Rapid response will often make or break an organization. HR players as facilitators instill a change agenda by assuring that organizations have the capacity and discipline to make change happen. Being a change agent is not enough. HR facilitators have to become speed mavens who are not only thought of as leaders, but also as practice masters for getting the organization to make things happen. As organization facilitators, they bring together resources, focus attention, and make sure that decisions are made quickly and accurately.
In many respects, we expect that the HR function will identify "strategic change leadership" of the firm's executives as a strategic capability. 
Facilitators ensure that action occurs within teams, organizations, and alliances.
Third, facilitators ensure that alliances operate. In the new economy, knowledge will not have to be owned to be accessed. Accessing knowledge and skills through alliances such as part ownership, joint projects, or partnerships becomes the bailiwick of the HR facilitator. Ensuring that ideas, competencies, authority, and rewards move across alliance boundaries becomes important for the rapid response required in the new economy.

In some ways facilitators are like coaches only instead of focusing on a person, they focus on collectives of people in teams, organizations, or alliances. Like coaches, they shape points of view and offer feedback on progress; however, facilitators have the more complicated task of working for collective groups of individuals, not just individuals.

\section{What Facilitators Do}

Facilitators ensure that action occurs within teams, organizations, and alliances. The guideposts for actions come from considering who is involved, what information is used, and how decisions are made. Involving the right people increases the probability of commitment. Since any group of individuals create relationships and political coalitions, HR facilitators must be aware of and sensitive to relationships and political agendas as they involve people in teams and alliances. Processing information enables facilitators access to influence and power. Since knowledge is power, facilitators need to process what information is required to make a decision and ensure access to accurate information. When facilitators are effective, they collect information that focuses on decisions and ensures action. Making decisions ensures that choices are made with speed and clarity. With the principles of involvement, information, and decisions, HR professionals may increase team, organization, and alliance operations.

HR facilitators increase teamwork when they monitor the quality of the team. They ensure that the right people are on the team to accomplish its goals, that the right information is generated to make good decisions, and that the team operates well. In facilitating teams, we have used a team checkup as a protocol to assess and improve teamwork. HR facilitators using a team checkup can take a team through a periodic (e.g., quarterly) team diagnosis:

- Purpose: To what extent does our team have a clear purpose? Do we know who the stakeholders are for the team and what they expect? Do we have a clear identity and set of goals we need to accomplish?

- Decisions: How well does our team make decisions? Are we too slow, too fast, too risky, not risky enough, too autocratic, not directive enough?

- Relationships: How well do we work together? How well do we handle conflict? Are we able to encourage differences and disagreement in private but create unity in public? Do we care for each other? Do we build an environment of trust and respect?

- Learning: How well do we learn from successes and failures? In the last three months what have we done well and what have we done poorly? What do we learn from both that we can apply to future teamwork?

Engaging teams in this type of diagnosis helps the members surface concerns and issues and increases team effectiveness. In one company, where such a diagnosis had not occurred, rifts that would have been minor and handled in a team checkup session became large and complicated and began to inhibit the accomplishment of team goals. At first, venting occurred as team members shared their concerns about each other, but, after the venting, commitment grew as facilitation helped the team collaborate for common goals.

HR facilitators help organizations make change happen fast when they build discipline into decision-making. Decision-making occurs when five protocols occur. First, gain clarity of the decision. A CEO of a large computer company has stated that no one can bring him an issue unless it has been boiled down to a "yes or no" response. This means that rather than start with information alone, it is imperative to be crystal clear about the decision that the information should help make. Rather than come to a meeting with the issue, "How 
do we gain better customer service scores?”, HR facilitators focus on a few key options and state those options explicitly: "I believe we can improve customer service scores by investing $\$ 50,000$ in a customer information and response system targeted on the top $10 \%$ of our customers; we should, therefore ...". This type of specific question then leads to more informed decision making.

Second, who makes the decision? Decisions may be delegated to an individual or a team, but it is critical that the individual or team know that $\mathrm{s} / \mathrm{he}$ is responsible. Individual accountability comes when a person realizes that $\mathrm{s} /$ he must sort through information and make a decision. In a similar way, team accountability comes when the team knows its charge and has accountability and responsibility for carrying through. HR facilitators ensure that an individual and/or team is clearly accountable for decisions that need to be made.

Third, when must decision be made? HR facilitators focus on when decisions must be made. They set timelines and hold people to them. The best deadlines have a public accountability - for example, a presentation to a senior management group or board of directors. With the commitment to a presentation, decisions will likely be made to accomplish the decision on time. In one company, we saw this effectively done: The leader of the team knew that a decision needed to be made. $\mathrm{He}$ sent an e-mail to all the team members on Monday morning stating that, on Friday at 9:00 a.m., a decision would be finalized to be presented to the executive committee. He laid out the question and parameters and wanted input by Tuesday at 5:00 p.m. Tuesday evening, he condensed this information and Wednesday morning sent out a synthesis of the input, asking for a second round. This information was collected by Thursday at noon, whereupon he crafted his recommendation for the executives that afternoon and sent it to the team. They had an opportunity that evening to make final comments before he prepared his remarks for the executives.

Some keys to this success are as follows: the decision was clear; the time frame was clear and anchored in a real event. With technology employees have access to information in ways that were unheard of very recently. Employees who did not participate did so at their own peril and risk. The three rounds enabled employees to have a voice in the decision, to have their input shared, and then to support final recommendations.

Fourth, what process is needed to make a good decision? The process for decision may include who needs to be involved, how accurate or risky the decision should be, and information required for a good decision. Using a good process ensures that commitment to a decision follows and that quality of decision increases.

Fifth, how will decision be returned and reported? Return and report implies that decisions need to stick, that decisions need to have accountability and follow-up to ensure that what is promised will be delivered. Return and report means that data is collected to track and monitor the decision, that people are publicly accountable for making a decision happen, and that follow-up occurs. Stickiness of decision increases when periodic reviews occur, when follow-up measures are tracked, and when incentives drive behavior.

HR facilitators increase organization capacity for speed when they ensure that ideas turn into decisions by deploying a decision protocol. As such, they become speed mavens who are competent and committed to organization action.

Finally, HR facilitators must create crossalliance actions and commitment. To do so, they must ensure that information moves across alliance boundaries, that knowledge in one firm is shared with another where the knowledge is needed, and that information systems connect people in different organizations. To do so, they must ensure that competence or talent flows across alliance boundaries. They create career paths that allow movement across company boundaries. They build training programs that involve participants from alliance partners. They create incentive programs that encourage joint problem solving. To do so, they ensure shared authority by creating cross-partner teams that collaborate to accomplish goals. When HR actions cross alliance boundaries, HR facilitators increase the probability that alliances deliver intended value.
Some keys to this success are as follows: The decision was clear; the time frame was clear and anchored in a real event. 
Effectively and efficiently

leading one's own HR function earns credibility.
In order to facilitate, HR professionals must learn skills in process observation. They need to be able to identify nuances of processes. These processes often include issues related to influence and power and facilitators know how to manage power and authority. In teams, organizations, and alliances, HR facilitators coordinate power to assure the authority to act. These processes also include resource allocation. HR facilitators know how to amass resources to accomplish goals. These processes include the ability to do team processing, organizational decision-making, and alliance management.

HR facilitation has a legacy in organization development (OD) work of HR. In OD work, HR professionals helped groups identify their charter and then learn how to collaborate to accomplish their charter. While some traditional OD work has been downplayed, the need to facilitate teams, organizations, and alliances continues.

\section{HR Leader: Creating Followers to Win}

Why HR Leaders Matter

We have worked in some companies where the senior HR leader advocates the above roles. $\mathrm{S} / \mathrm{he}$ coaches leaders, architects capabilities, builds HR practices, and facilitates change, but $\mathrm{s} /$ he has no credibility. S/he does not manage his/her own function. S/he does not practice what s/he preaches. In cases such as these, business leaders often pay attention to what they see more than what they hear.

Effectively and efficiently leading one's own HR function earns credibility. In a number of cases, we have seen new heads of HR appointed and immediately face the challenge of running their function. In some cases, this has meant that a disgruntled or dysfunctional employee with whom the previous leader had not dealt needed to be managed and/or exited from the firm. Senior HR professionals who did not face up to and implement HR practices within their own functions lose credibility as they advocate ideas to others.

\section{What HR Leaders Do}

The HR function should be the exemplar of how to manage an effective department. As an exemplar, HR should be run as a business. As a business, HR needs the same elements of a business plan:

- Business realities: What are the strategic priorities of the business? An HR business plan begins with "the" business plan. The presentation a senior business leader would make to the board of directors should also be the first plank of an HR business plan.

- HR vision: An HR vision articulates in few words the aspirations of the HR function. An HR vision answers three questions: (1) Who are we (e.g., partners, players, architects, etc.)? (2) What do we do (e.g., increase individual and organizational capability)? (3) Why do we do it (e.g., to build competitiveness, to increase shareholder or customer value)?. An HR leader should craft such a vision quickly and simply.

- Deliverables: HR should focus on deliverables more than on doables. HR deliverables represent capabilities the firm requires to serve customers and intangibles the firm uses to build shareholder value. We advocate that strong HR departments have three to five deliverables on which they focus.

- HR investments: The HR choices advocated for the firm in the building role need to be applied within HR. HR leaders need to pay attention to HR competence, training, rewards and recognition, communication, and governance. When HR practices used for the firm are also deployed within HR, they have more credibility and legitimacy. Too often we see HR professionals not receiving training or performance reviews that they manage and advocate for others.

- HR governance: HR investments may be implemented by line managers; HR professionals in centers of expertise, service centers, corporate, or business units; and/or external alliance partners. HR leaders must determine who has what accountability and responsibility for HR to ensure that work of HR is governed appropriately. 
- HR measures and actions: HR leaders need to prepare accountable action plans to track and monitor the performance of the HR function and HR practices. These measures create a balanced scorecard for HR and actions that may lead to actions to increase scores on this scorecard.

- HR professionals: HR leaders need to increase the quality of their HR professionals by continually articulating and investing in HR professional development.

The above seven elements of an HR plan imply that HR is run like a business, with context, vision, strategy, and priorities.

This HR business plan should be shared both inside and outside the HR function. Inside, it should serve as a compass for HR action, offering direction and intention. Outside, it should increase the credibility of the HR function because the function practices what it preaches and models good leadership behavior.

In order to lead, HR players need to apply a leadership model to themselves. The leadership model we advocate follows a simple equation: Effective leadership equals attributes times results. Attributes means leaders know and do things that ensure they do things the right way. Results mean that leaders ensure outcomes from their knowledge and actions. HR leaders need to define clearly the behaviors they should demonstrate as leaders (e.g., setting clear goals, being decisive, communicating inside and out, and managing change). They also must define clearly the results they must deliver.

\section{HR as Conscience: Playing by the Rules to Win}

\section{Why Conscience Matters}

One role that is too often overlooked is that of ensuring that organizations play by the rules. Organizations need internal referees who demand that rules are followed. Somewhere in the organization someone must hold a mirror up to executive teams, to employees, and to the HR function. A mirror reflects in unflinch- ing candor actions taken within a firm that erode leadership credibility, for example, leaders who say one thing and do another. The marketplace punishes such organizations and so do employees. Many candidates exist for internal referee including the financial and legal functions but often they access issues too late and are unable to create the change before facing a risk with negative consequences. What might be considered good or normal business practice such as restated earnings, violations of FASB practices often invite litigation (e.g., Xerox, IBM, ConAgra, McKesson HBOC, etc.). These issues are critical. HR can and should be this mirror.

This role requires understanding of both the moral and ethical rules by which the game is played. HR plays the referee role to ensure that the organization wins the right way. Playing by the rules avoids winners being stripped of titles and victories because they may have chosen not to play by the rules. Someone somewhere has to be willing to have the courage to "put it on the line" and call things as they are. Perhaps by default, perhaps by intent, but in some way, HR must have the courage and assure that this function is filled in organizations. The role of the conscience of the organization for the HR professional may be absolutely essential and in several respects may provide the greatest ultimate value to the organization.

\section{What Conscience Referees Do}

We have observed or been of counsel to many organizations (usually after the fact) that have experienced such problems. Often the HR professional was kept in the dark on these issues or was aware of them and struggled over what to do. These issues have included EEO violations, environmental pollution, sexual harassment, overstated/questionable reporting of sales figures, and the use of incentives for questionable business practices. We suggest that those aspiring to be HR players develop a moral compass and continue to examine each business practice against the following three criteria:

- Green (practice or activity is $\mathrm{OK}$ ) After examination, an HR professional establishes that a practice is not only
This HR business plan should be shared both inside and outside the HR function. 
in the best interest of the business but would without question withstand the judgment of relevant external constituents.

- Yellow (practice or activity is questionable)

These are issues that have failed the "smell test" from the perspective of the firm's stakeholders. When this occurs, it is best to begin to include trusted others who are in tune with the organization's moral compass on the issues in question. Such confidants should be chosen by the HR professional because of their competency and concern for the organization's longterm well-being, and the principles that seem to guide their lives. If these contacts, upon honest evaluation, give the "green light" to a practice with a rationale that is understood, acceptable, and easy to others, the practice may be green-lighted. However, if not . . .

- Red (practice or activity is dubious) This is the area where the HR professional not only feels the firm is vulnerable, but s/he is personally vulnerable, especially if this vulnerability concerns what are generally considered HR issues. The obviously difficult issues must be brought to the attention of higher management. In such instances, the HR professional must be willing to put his/her job on the line. This is where HR professionals "draw the line in the dirt" and let the organization know it has gone too far. In many of these instances, letters are written to the CEO, board chairperson, and often the corporate counsel's office, sometimes with the advice of an attorney whom the HR professional has retained. In some instances, the responses are positive, and the firm takes remedial action, demanding actions that preclude repetition of similar events. In others, the organization may exit the HR professional (whistleblower). The HR professional clearly must recognize the consequences of sending such letters. These are never pleasant experiences and various forms of retaliation may follow. In one problematic circumstance, we witnessed an HR executive being told by other executives that "You know people will contact us for references". The actions in these instances are irreversible, and it must be understood that once the message is sent that the organization will respond and will respond quickly.

\section{Emerging Roles of the HR Player}

Above we describe the emerging roles of the successful HR player in the future. These roles will be those sought by organizations that recognize that management of the workforce, both by line managers and HR professionals, must be a significant component of the organization. To enable these roles to occur, the six roles described above must be fulfilled within the organizational context in order to build winning organizations.

HR players who can fulfill these roles of coach, architect, builder, facilitator, leader, and conscience will not only be sought by their own organizations but by others. It is no longer sufficient in many organizations for the role of HR to merely be polite, police, or merely desiring to become a member of the management committee of organization. The objective of HR professionals is to ensure that $\mathrm{HR}$ adds value to strategic planning and business results of organizations. By fulfilling these roles, HR professionals become valued contributors at the strategic decision-making and strategy execution meetings within organizations. 
Dave Ulrich is Professor of Business Administration at the University of Michigan. He studies how organizations build capabilities of changing fast, learning, ensuring leadership brand, nurturing talent, and instilling a shared mindset through HR activities. He has published over 90 articles and book chapters. His most recent books are Results Based Leadership (with Norm Smallwood and Jack Zenger) (Boston: Harvard Business Press), HR Scorecard (with Brian Becker and Mark Huselid) (Boston: Harvard Business Press). He was the Editor, Human Resource Management Journal (1990-1999) and serves on the board of directors for Herman Miller.

Richard W. (Dick) Beatty is Professor of Human Resource Management at Rutgers University and is a Core Faculty member at the University of Michigan's Executive Education Center. He received his B.A. from Hanover College, his M.B.A. from Emory University, and his Ph.D. in Human Resources and Organizational Behavior from Washington University. He has published several books, more than 100 articles, and is an associate editor of Human Resource Management. He was president of the Society for Human Resource Management Foundation and received the society's book award. He also twice won the research award from the Human Resource Planning Society.

\section{REFERENCES}

Beatty, R.W., \& Schneier, C.E. (1996). New HR roles to impact organizational performance: From partners to players. Human Resource Management, 35(Special Issue).

Christensen, C., \& Overdorf, M. (2000). Meeting the challenge of disruptive change. Harvard Business
Review, (March-April), 67-76.

Heskett, J., \& Schlesinger, L. (1994). Putting the service-Profit chain to work. Harvard Business Review, (March-April), 167-174.

Ulrich, D., \& Lake, D. (1990). Organizational capability: Competing from the inside out. New York: Wiley. 